\title{
Les récepteurs aux œstrogènes dans le testicule et l'appareil reproducteur du primate et de l'homme
}

\author{
Philippa T.K. SAUNDERS, Jayne E. SIERENS, Niegel P. GROOME*, Michael R. MILLAR \\ MRC Human Reproductive Sciences Unit, Centre for Reproductive Biology, \\ The Chancellor's Building, 49 Little France Crescent, Edinburgh EH16 4SB, UK. \\ ${ }^{*}$ School of Biological \& Molecular Sciences, Oxford Brookes University, \\ Gypsy Lane Campus, Headington, Oxford, OX3 OPB, UK.
}

\section{RESUME}

L'impact des œstrogènes sur le système reproducteur mâle est le sujet d'intenses débats et l'objet d'une intense activité de recherche. L'action des cestrogènes a lieu par l'intermédiaire de récepteurs intracellulaires de forte affinité, exprimés au niveau des tissus cibles. Deux sous-types de récepteurs aux œstrogènes, connus sous les noms de RE $\alpha$ (NR3A1) et RE $\beta$ (NR3A2) ont été clonés, et des isoformes variants de $h R E \beta$ identifiés. Dans les cellules cibles, ces récepteurs peuvent exister sous forme d'homo ou d'hétéro-dimères. Nous avons utilisé une approche immuno-histochimique pour étudier les profils d'expression des RE chez l'homme et les primates non humains comme première étape de la détermination des cibles cellulaires de l'action des cestrogènes chez le mâle.

Le RE $\alpha$ a été détecté dans les cellules épithéliales des canaux efférents (CE), occasionnellement dans les cellules de l'épithélium et du stroma épididymaires, mais jamais dans les testicules d'humains ou de primates. En utilisant un anticorps polyclonal contre la région charnière du $\operatorname{RE} \beta$, un marquage immunopositif fut détecté dans de très nombreux types cellulaires dans le testicule, ainsi que dans les noyaux des cellules de l'épithélium et du stroma tout au long de l'appareil reproducteur mâle (CE, épididyme, canal déférent, vésicules séminales, prostate) et dans la vessie. Nous avons aussi utilisé des anticorps monoclonaux qui font la distinction entre la forme complète du type sauvage de $\operatorname{RE} \beta$ (RE $\beta 1$ ), et un isoforme variant tronqué dénommé $R E \beta c x / R E \beta 2$ qui ne se lie pas aux œstrogènes. Les protéines $R E \beta 1$ et $R E \beta 2$ furent toutes les deux détectées dans le testicule humain et pos- sèdent des profils d'expression distincts, mais qui se chevauchent. Le RE $\beta 1$ fut aussi détecté dans les $\mathrm{CE}$, l'épididyme et le canal déférent.

En conclusion, les récepteurs aux œstrogènes sont largement exprimés dans l'appareil urogénital mâle et, à l'exception des CE, il existe plus de cellules exprimant RE $\beta$ que RE $\alpha$. Chez l'homme adulte, les cellules testiculaires qui constituent probablement les cellules cibles des œstrogènes sont les spermatides rondes dans lesquelles les taux d'expression de la forme complète du type sauvage du récepteur (RE $\beta 1)$ sont élevés.

Mots-clés : spermatogénèse, récepteur œstrogène, $R E \beta$, spermatides

\section{Correspondance :}

Dr Philippa Saunders - MRC Human Reproductive Sciences Unit, The Chancellor's Building, 49 Little France Crescent, Edinburgh, EH16 4SB, UK - Email: p.saunders@ed.ac.uk 


\section{INTRODUCTION}

L'action des œstrogènes a lieu par l'intermédiaire de récepteurs intracellulaires à haute affinité exprimés dans les tissus cibles. Après liaison du ligand, les récepteurs subissent une transformation conformationnelle, se dimérisent, lient leurs régions régulatrices avec des gênes, recrutent des co-facteurs et ainsi régulent la tanscription des gènes cibles (pour une revue récente, voir $[20,28]$ ). Deux ADNc de récepteurs aux eostrogènes, connus comme RE $\alpha$ (NR3A1) et RE $\beta$ (NR3A2), codés par des gènes localisés sur différents chromosomes [8], ont été clonés à partir de tissus d'humains et de rongeurs $[14,26$, 31 ].

Comme d'autres membres de la super-famille des récepteurs aux stéroïdes, les deux récepteurs ont une structure commune avec succession de cinq domaines fonctionnels, dénotés A-F [3]. En 1998, un nouveau variant humain $R E \beta$, dénommé $R E \beta c x$, fut identifié dans une banque d'ADNc de testicule humain (accession AB006589). Dans différentes expérimentations, Moore et al. [25] ont identifié un certain nombre d'ARNm dans des tissus humains, y compris le testicule, qui codent pour des isoformes du hRE $\beta$ incluant une isoforme identique à hRE $\beta \mathrm{cx}$ qu'ils ont dénommée hRE $\beta 2$ (revue dans [43]). Pour éviter toute confusion, la protéine originale hRE $\beta$ identifiée comme homologue du RE $\beta$ du rat sera appelée $h R E \beta 1$ et le variant d'épissage $h R E \beta c x / h R E \beta 2$ sera appelé hRE $\beta 2 / \beta \mathrm{cx}$ dans la suite du présent article (Figure 1).

Dans le testicule adulte, la testostérone est synthétisée par les cellules interstitielles de Leydig [35] et de nombreuses études ont montré que les concentrations de testostérone à l'intérieur du testicule atteignent des valeurs jusqu'à 100 fois celles observées dans la circulation générale [23]. En outre, la testostérone est localement convertie en œstrogènes par l'aromatase $\mathrm{P} 450$ qui est exprimée dans les cellules de Leydig [34], les cellules germinales haploïdes $[4,46]$, et les spermatozoïdes [15].

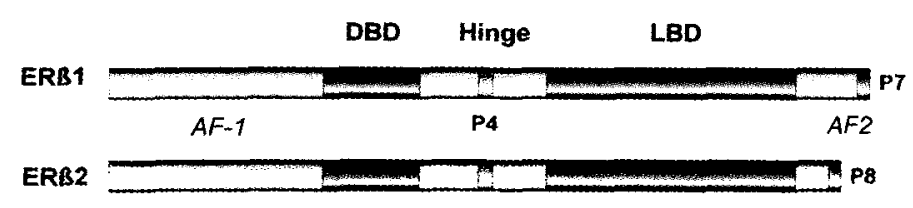

Figure 1 : Représentation schématique du RE $\beta 1$ humain (type sauvage) et du variant d'épissage (c-terminal) humain $R E \beta 2 / \beta c x$. Les positions des domaines de liaison à l'ADN $(D B D)$, de liaison du ligand $(L D B)$ et de la région charnière $(H)$ sont montrés en fonction des peptides (P4, 77 et $P 8)$ utilisés pour la fabrication des anticorps spécifiques.

\section{MATERIEL ET METHODES}

\section{Tissus}

Les tissus testiculaires furent obtenus d'hommes $(n=7)$ lors d'investigations chirurgicales : les hommes ont tous donné un consentement éclairé. Les canaux déférents ont été obtenus d'hommes réalisant une vasectomie. Les autres tissus humains provenaient de la banque de tissus du Perterborough Hospitals NHS Trust.

Les prélèvements de tissus réalisés sur des ouistitis d'espèce commune (Callthrix jacchus) et des macaques à queue en tire-bouchon (Macaca arctoides) en captivité, ont été décrits précédemment [41]. Tous les tissus ont été fixés dans du Bouin et traités selon les méthodes standard.

\section{Anticorps}

L'anticorps monoclonal de souris contre RE $\alpha$ humain a été obtenu de DAKO (Cambridge, UK, clone ID5). Les protéines REß ont été détectées par utilisations de trois anticorps différents, les localisations des peptides utilisés pour les générer sont montrés à la Figure 1. Tout d'abord, un antisérum polyclonal de mouton a été immuno-purifié à l'aide du peptide $\mathrm{P} 4$ (région charnière) du hREß, et a été validé comme décrit par ailleurs [40] ; après quoi, deux anticorps monoclonaux spécifiques de souris contre REß1 (type sauvage, peptide $\mathrm{P} 7$ ) et contre $\mathrm{REB2} / \mathrm{Bcx}$ (peptide 8) ont été préparés et validés comme déjà décrit en détail [40,42]. La spécificité des anticorps a été confirmée par Western-Blotts $[40,42]$.

\section{Immuno-histochimie}

Les coupes ont été soumises à la chaleur pour exposer les antigènes comme rapporté dans [41], saturées pendant 30 mn par du sérum de lapin normal (NRS : Diagnostics Scotland, Carluke, UK) dilué 1:4 dans du TBS contenant $5 \%$ de sérum albumine bovine (NRS/TBS/BSA). Les anticorps furent dilués $(\operatorname{RE} \alpha, 1: 50$; RE $\beta, 1: 800$; RE $\beta 1,1: 50$; REß2, 1:50) dans le NRS/TBS/BSA puis mis en contact avec les coupes à $40^{\circ} \mathrm{C}$ pendant toute la nuit. Les coupes furent lavées avec du TBS et incubées avec les anticorps secondaires biotinylés appropriés : anticorps de lapin antimouton (Vector) pour l'antiRE $\beta$, et anticorps de lapin antisouris (DAKO, Cambridge, UK) pour l'antiRE $\alpha$, chacun étant dilué au 1:500 dans le NRS/TBS/BSA. Après lavages dans le TBS, les coupes furent incubées avec le complexe avidine-biotine-peroxidase de raifort (DAKO) selon les indications du fabricant. L'anticorps lié fut visualisé en utilisant de la 3,3'-diaminobenzidine tétrahydrochloride (DAKO). Les coupes furent contre-colorées à l'hématoxyline et les images ont été faites à la caméra Kodak DCS330 (Eastman Kodak), mises en réserve sur un ordinateur personnel Macintosh, puis assemblées à l'aide de Photoshop 6.0 (Adobe, Mountain View, CA). 


\section{RESULTATS}

\section{Récepteur alpha aux æestrogènes}

Les cellules positives pour le RE $\alpha$ furent détectées dans la couche épithéliale des canaux efférents (CE) de chacune des trois espèces examinées (Figure 2a, macaque). Pour le reste de 1'appareil reproducteur, la plupart des cellules épithéliales furent immunonégatives, bien que d'occasionnelles cellules immuno-positives aient été observées dans les épididymes de ouistiti et de macaque (voir [41]), et dans la population de cellules basales de la prostate humaine. Les cellules positives au RE $\alpha$ furent détectées dans le stroma des vésicules séminales (Figure $2 b$ ), de la prostate et de la vessie (Tableau 1).

\section{Récepteur béta aux oestrogènes}

En utilisant un anticorps dirigé contre la région charnière du RE $\beta$ humain [40], des noyaux de cellule immuno-positifs furent détectés dans les testicules et tout au long de l'appareil reproducteur mâle. Par exemple, des cellules RE $\beta$ positives étaient présentes à la fois dans l'épithélium et le stroma des CE (Figure 2c), des épididymes, du canal déférent, de la vésicule séminale, de la prostate (Figure 2d) et de la vessie. Les résultats sont résumés au Tableau 1. Dans le testicule, les cellules somatiques (Sertoli, cellules myoïdes péritubulaires, Leydig) aussi bien que les cellules germinales pré-méiotiques (par exemple les spermatogonies) et post-méiotiques (par exemple les spermatides) sont toutes immuno-positives.

\section{Variants du récepteur béta aux œstrogènes}

Bien que de très nombreux noyaux cellulaires aient été colorés par l'anticorps dirigé contre la région charnière du RE $\beta$ (voir ci-dessus), lorsqu'on appliqua aux coupes de testicules humains (Figure 2c) et de primates (Figure 2f, macaque) des anticorps monoclonaux dirigés contre la partie C-terminale de la totalité de la protéine RE $\beta$, seul un sous-ensemble de cellules furent immuno-positives. La réaction immuno-positive la plus intense fut détectée dans les spermatides rondes (par exemple, chez l'homme, Figure $2 \mathrm{~g}$, marquées $\mathrm{R}$ ), et une coloration immuno-positive fut rarement détectée dans les cellules de Sertoli. A l'inverse, quand l'anticorps dirigé contre la partie C-terminale de l'isoforme variant d'épissage de RE $\beta 2$ fut appliqué aux mêmes coupes, la coloration immuno-positive la plus intense fut localisée dans les noyaux des cellules de Sertoli (Figure 2h, flèche) ainsi que dans un petit nombre de cellules germinales situées à la périphérie des tubules séminifères, cellules qui furent identifiées apparemment comme des spermatogonies. Un résumé du profil d'expression des RE dans le testicule humain adulte est rapporté au Tableau 2.
Les différences entre les séquences au niveau C-terminal des variants REß2 du macaque et du ouistiti d'une part, et celles de l'homme d'autre part, signifient que l'anticorps antiREB2 ne colore pas les tissus de ces espèces (G.A. Scobie et J.E. Sierens, observations non publiées). Les études préliminaires utilisant l'anticorps monoclonal dirigé contre le peptide 7 (fragment C-terminal de la protéine de type sauvage) sur des coupes de CE, d'épididyme et de canal déférent d'humains et de macaques révèlent que la plupart des cellules identifiées comme positives à REß avec l'utilisation de l'anticorps anti-P4 étaient aussi positives avec l'anticorps anti-C-terminal, suggérant que la totalité de la protéine fonctionnelle était exprimée. Quelques cellules de l'épithélium et du stroma de l'épididyme et du canal déférent humains furent aussi REB2 positives (résultats non montrés).

\section{DISCUSSION}

L'impact des œstrogènes sur la fertilité mâle a été exploré en suivant plusieurs pistes différentes, tout d'abord, comme dans la présente étude, en définissant le profil d'expression des récepteurs aux oestrogènes, ensuite en manipulant l'environnement hormonal, avec par exemple l'administration d'œstrogènes ou d'anti-œstrogènes, et finalement par l'ablation ciblée de gènes chez la souris. Chacune de ces trois approches a contribué à notre compréhension des sites d'action des œestrogènes et a conduit à la conclusion générale que la fécondité masculine pouvait être affectée par les œstrogènes comme par les androgènes $[29,30]$.

Une partie des données les plus convaincantes d'un rôle des œestrogènes dans le développement des cellules germinales provient d'études de knockout de l'aromatase (ArKo) chez la souris. Bien que les mâles ArKo soient initialement féconds, une infécondité est observée chez les animaux adultes à partir de l'âge de 4 mois 1/2 [9]. Les analyses des testicules de ces animaux ont montré que les spermatides rondes subissent une apoptose, qu'elles présentent des perturbations de la formation de l'acrosome et qu'elles sont incapables de se différencier en spermatides matures allongées [36, 37]. En accord avec ces données qui suggèrent que les œstrogènes pourraient agir comme facteur de survie des cellules germinales, le traitement des singes par un inhibiteur de l'aromatase résulte aussi en une réduction de la transformation de spermatides rondes en spermatides allongées [44]. En outre, chez les souris qui développent des tubules séminifères immatures sans développement complet des cellules germinales en raison d'une déficience des taux de gonadotrophines (le modèle de souris hpg [5]), le traitement des animaux par de faibles quantités d'oestradiol pendant 70 jours résulte en une multiplication par $5 \mathrm{du}$ poids des testicules et en une spermatogenèse quantitativement normale [6]. 

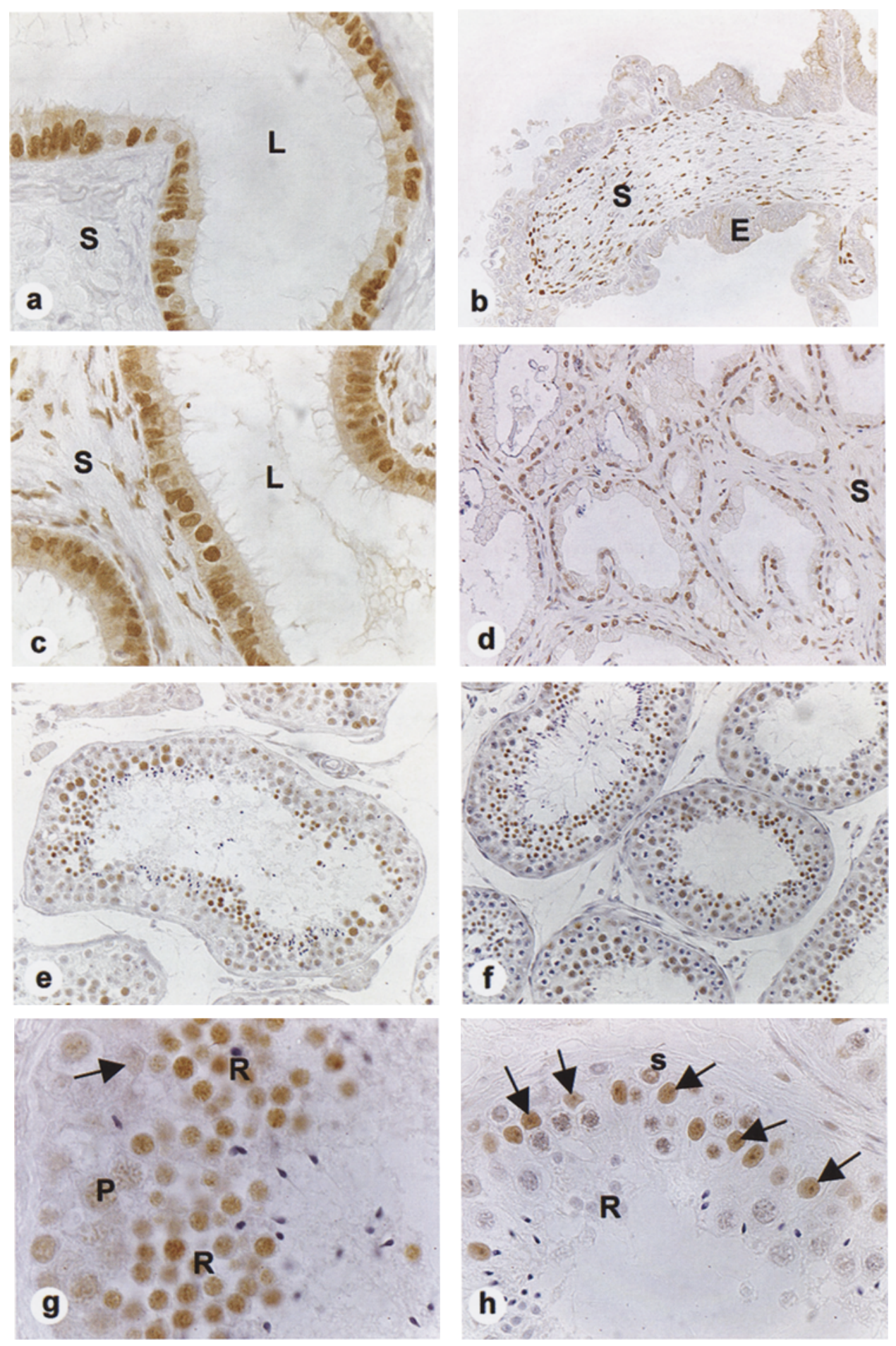

Figure 2 : Localisation immunologique des récepteurs aux aestrogènes dans des tissus prélevés chez le mâle.

a) Marquage immuno-positif pour RE $\alpha$ dans les canaux efférents de macaque : noter le marquage intense des cellules épithéliales .

b) Vésicule séminale de ouistiti : des cellules positives pour RE $\alpha$ ne sont retrouvées que dans le stroma, pas dans l'épithélium ;

c) Marquage immuno-positif pour RE $\beta$ dans des canaux efférents de macaque (coupe parallèle à celle montrée à la planche a);

d) Noyaux de cellules immuno-positives pour $\mathrm{RE} \beta \dot{a}$ la fois au niveau de l'épithêlium et du stroma de tissu prostatique provenant de ouistiti;

e) Testicule humain marqué avec un anticorps spécifique de la région C-terminale du RE $\beta 1$;

f) Testicule de macaque marqué avec un anticorps spécifíque de la région C-terminale du RE $\beta 1$;

g) Au grossissement 100, testicule humain marqué avec un anti-RE $\beta 1$ : noter la réaction immuno-positive intense dans les spermatides rondes $(R)$, mais faible dans les cellules de Sertoli (flèche) et les spermatocytes pachytènes $(P)$;

h) Au grossissement 100, testicule humain marqué avec un anti-RE $\beta 2 / \beta c x$ : noter la réaction immuno-positive intense des noyaux de cellule de Sertoli (flèches) et des spermatogonies (S); 
Tableau 1 : Comparaison entre les profils d'expression des RE $\alpha$ et RE $\beta$ dans l'appareil reproducteur mâle chez l'humain et les primates non humains.

\begin{tabular}{|c|c|c|c|c|}
\hline \multirow[t]{2}{*}{ Tissu } & \multicolumn{2}{|c|}{$\mathbf{R E} \alpha$} & \multicolumn{2}{|c|}{ RE $\beta$ (région charnière) } \\
\hline & Epithelium & Stroma & Epithelium & Stroma \\
\hline Canaux efférents & ++++ & $?$ & ++ & + \\
\hline Tête de l'épididyme & $-1+$ & - & +++ & ++ \\
\hline Corps de l'épididyme & $-1+$ & - & +++ & + \\
\hline Queue de l'épididyme & $-1+$ & - & ++ & + \\
\hline Canal déférent & - & - & ++ & ++ \\
\hline Vésicules séminales & - & ++ & ++ & + \\
\hline Prostate & $-1+$ & + & ++ & + \\
\hline Vessie & - & + & +++ & + \\
\hline
\end{tabular}

Tableau 2 : Résumé des profils d'expression cellulaire spécifique des récepteurs aux astrogènes dans le testicule humain adulte.

\begin{tabular}{|c|c|c|c|}
\hline Type cellulaire & $\mathbf{R E} \alpha$ & REB1 (type sauvage) & REB2/ßCX \\
\hline Cellule de Sertoli & - & $(+)$ & +++ \\
\hline Spermatogonie & - & $(+)$ & +++ \\
\hline SpermatocyteI & - & & \\
\hline Pré Leptotène & - & $(+)$ & $(+)$ \\
\hline Leptotène & - & $(+)$ & $(+)$ \\
\hline Zygotène & - & $(+)$ & $(+)$ \\
\hline Pachytène & - & $+/++$ & + \\
\hline Diacinèse & - & $(+)$ & + \\
\hline Spermatocyte II & - & +++ & - \\
\hline Spermatide ronde & - & +++ & - \\
\hline Spermatide allongée & - & - & - \\
\hline Cellule de Leydig & - & $(+)$ & $(+)$ \\
\hline Cellules péritubulaires myoïdes & - & + & ++ \\
\hline
\end{tabular}


Nous avons montré, à la fois chez l'homme et le primate, que la plupart des cellules épithéliales des canaux efférents (CE) exprimaient à la fois les récepteurs nucléaires $R E \alpha$ et REB (le présent article et [41]), et des résultats similaires ont été rapportés chez la chèvre [13], le chien et le chat [27], le rat $[10,17]$, et la souris [50]. Les CE sont un lieu important de résorption de liquide dans le système reproducteur mâle $[16,18]$. Un rôle des cstrogènes dans la modulation de la fonction des CE a été mis en évidence par des études menées chez les rongeurs. Par exemple, chez la souris knockout pour le RE $\alpha$ (ERKO [21, 22]), les mâles deviennent inféconds en raison de l'accumulation excessive de fluide dans la lumière des tubules séminifères, ce qui entraîne des dommages irréversibles à l'épithélium séminifère [7]. De la même façon, on a montré que l'administration d'un anti-œstrogène à des rats entraînait une réduction de la résorption de fluide dans les $\mathrm{CE}$, ce qui résulta en une dilatation des canaux et une augmentation du poids du testicule [33]. On a montré que les œstrogènes étaient essentiels à l'expression d'une protéine de transport du sodium par les CE et à la morphologie des cellules épithéliales [49]. Il est à remarquer que chez les souris ERKO, l'expression de REB dans les canaux efférents peut encore être détectée, mais est clairement non suffisante au maintien de la compétence fonctionnelle normale des cellules épithéliales.

De nombreuses études ont montré que la plupart des cellules de l'épithélium tapissant l'épididyme et le canal déférent expriment le RE $\beta[2,27,41,50]$. L'expression de $\mathrm{RE} \alpha$ est généralement rapportée comme étant plus abondante dans les cellules du stroma que dans les cellules des épithélia, bien qu'il apparaisse y avoir quelques différences entre les espèces. Par exemple, dans l'épididyme du ouistiti [41] et du chien [27], peu de cellules épithéliales positives au RE $\alpha$ ont été détectées, alors que chez la souris [50] et le chat [27], un nombre significatif de cellules épithéliales sont immuno-positives au RE $\alpha$. Chez le rat, l'exposition en période néonatale à de fortes doses du puissant ostrogène qu'est le diethylstilbestrol (DES) entraîne des anomalies dans la spécificité cellulaire et régionale de l'expression de RE $\alpha$, ce qui suggère que les œstrogènes jouent un rôle dans le développement péripubertaire de l'épididyme et du canal déférent [1]. Des études chez la souris ont montré que l'enzyme ostrogène sulphotransférase (EST) était aussi exprimée dans les cellules épithéliales du corps et de la queue de l'épididyme ainsi que dans les cellules de l'épithélium et les cellules musculaires lisses du canal déférent [45]. Des études dans lesquelles l'expression de EST a été modulée (knockouts, manipulations hormonales) ont suggéré que cette enzyme jouait un rôle en modulant l'homéostasie des œstrogènes, et que des perturbations des taux d'œstrogènes dans l'environnement luminale de l'épididyme pouvaient avoir un effet négatif sur la mobilité des spermatozoïdes [45]. Plusieurs études ont montré que l'exposition à des taux élevés d'œstrogènes pouvait altérer l'expression des gènes dans d'autres parties de l'appareil reproducteur mâle. Par exemple, Williams et al. [48] ont rapporté que le traitement en période néonatale par du DES entraînait une réduction de l'expression des récepteurs aux androgènes mais induisait aussi une expression des récepteurs à la progestérone dans le stroma des vésicules séminales de rats âgés de 18 jours.

Comme d'autres, nous avons toujours échoué à détecter l'ARNm ou la protéine RE $\alpha$ dans des échantillons de testicules humains [24, 41, 42], de ouistiti ou de macaque (données non publiées). Ces résultats sont en opposition flagrante avec ceux obtenus chez d'autres espèces incluant les rongeurs $[10,50]$, le chien et le chat [27] chez lesquels le RE $\alpha$ est exprimé dans les cellules de Leydig et aussi dans les cellules péri-tubulaires chez certaines espèces.

On a, au contraire, rapporté que les protéines REß étaient exprimées dans de nombreux types cellulaires incluant les cellules de Sertoli, les cellules germinales pré et postméiotiques, les cellules de Leydig et les cellules péri-tubulaires chez le rat $[39,47]$, la souris [50], le chien et le chat [27], les primates [41] et les humains [24, 41]. De plus, on a identifié des ARNm codant pour les isoformes variants de REß, formés par épissage alternatif du gène, dans des ADNc préparés à partir de testicules humains $[19,25,32$, 43]. Nous avons précédemment fabriqué des anticorps spécifiques du récepteur de type sauvage sous sa forme complète et de trois des variants d'épissage et nous avons montré que les protéines pour lesquelles ils codent sont exprimées dans le testicule humain pendant la vie fotale [12] et à l'âge adulte [42], ainsi que dans d'autres tissus y compris le canal déférent [43].

A ce jour, la signification fonctionnelle de l'expression des protéines de variants d'épissage du REß humain a été étudiée en utilisant des cellules co-transvectées avec de l'ADNc codant pour l'isoforme variant et des plasmides contenant l'ADNc complet soit du hRE $\alpha$, soit du hREß $[19,32]$. Dans ces études, il a été montré que l'isoforme variant (qui ne lie pas le ligand) agissait comme un régulateur dominant négatif de l'activation du gène reporter par le $R E ß$ en présence d'oestradiol. La protéine du variant REB2/Bcx, que nous avons localisée immunologiquement dans le testicule au niveau des cellules de Sertoli et des spermatogonies (présent article et [42]), a aussi été localisée par immunologie dans des échantillons de tissus mammaires normal et malin [38] et de prostate [11]. Une expression augmentée de REB2/Bcx va de pair avec une moindre expression du récepteur à la progestérone dans les cellules malignes [38]. Pour ce qui est du testicule humain, la co-expression de REB2 et de RE $\alpha$ n'a pas été observée, et le REB2/bcx apparaît être la seule forme de protéine du 
RE présente dans certaines cellules (par exemple les cellules de Sertoli). Nous mettons actuellement en place des études pour déterminer la signification fonctionnelle de ces découvertes.

En utilisant l'immuno-histochimie avec un anticorps monoclonal spécifique [42], nous avons détecté l'expression de la protéine du RE $\beta$ sous sa forme complète, c'està-dire l'isoforme qui est capable de lier une gamme de ligands oestrogéniques avec une haute affinité et qui peut activer in vitro l'expression du gène reporter chez de très nombreux types cellulaires tout au long de l'appareil reproducteur mâle. Dans le testicule adulte de l'homme, du ouistiti et du macaque, les taux d'expression les plus élevés furent détectés dans les spermatides rondes. L'expression du RE $\beta$ dans ces cellules apparaît consistante avec les données établies à partir d'études chez les rongeurs et les primates $[36,37,44]$, ce qui suggère que les œstrogènes sont importants pour la maturation des cellules germinales haploïdes ainsi que pour la résorption du fluide dans les canaux efférents.

\section{CONCLUSIONS}

Il est maintenant établi que les œestrogènes ont un rôle dans la maintenance de la fécondité normale du mâle. Dans l'appareil reproducteur mâle, les cellules qui expriment le REB sont plus nombreuses que celles exprimant le RE $\alpha$. Les taux d'expression de RE $\alpha$ les plus élevés ont été retrouvés dans les canaux efférents et l'expression de RE $\alpha$ dans ce tissu est essentielle à une résorption normale du fluide provenant des tubules séminifères. La protéine du REB a été détectée dans les cellules épithéliales et du stroma tout au long de l'appareil reproducteur chez le mâle. Dans les testicules des primates et de l'homme sont exprimées les protéines de REB à la fois de type sauvage et variants. En s'appuyant sur les profils d'expression des protéines du REB dans l'épithélium séminifère de l'homme, nous pensons que les astrogènes pourraient être importants pour le développement des spermatides rondes et de certains des spermatocytes, mais pas de tous.

\section{REMERCIEMENTS :}

Les auteurs remercient Sheila Macpherson, Keith Morris et Graeme Scobie pour leur assistance technique, et les Drs D.S. Irvine et H.M. Fraser pour la fourniture des échantillons de tissus.

\section{REFERENCES}

1. ATANASSOVA N., MCKINNELL C., TURNER K.J. et al. : Comparative effects of neonatal exposure of male rats to potent and weak (environmental) estrogens at puberty and the relationship to adult testis size and fertility : evidence for stimulatory effects of low estrogen levels. Endocrinology, 2000, 141 : 38983907.

2. ATANASSOVA N., MCKINNELL C., WILLIAMS K. et al. : Age-, cell- and region-specific immunoexpression of estrogen receptor alpha (but not estrogen receptor beta) during post natal development of the epididymis and vas deferens for the rat and disruption of tbis pattern by neonatal treatment with diethylstilbestrol. Endocrinology, 2001, $142:$ 874-886.

3. BEATO M., KLUG J. : Steroid hormone receptors : an update. Hum. Reprod. Update, 2000, 6 : 225-236.

4. CARREAU S., GENISSEL C., BILINSKA B., LEVALLET J. : Sources of oestrogen in the testis and reproductive tract. Int. J. Androl., 1999, 22 : 211-223.

5. CATTANACH B.M., IDDON C.A., CHARLTON H.M., CHIAPPA S.A., FINK G. : Gonadotrophin-releasing hormone deficiency in a mutant mouse with hypogonadism. Nature, 1977, $269: 338-340$.

6. EBLING F.J.P., BROOKS A.N., CRONIN A.S., FORD H., KERR J.B. : Estrogenic induction of spermatogenesis in the hypogonadal mouse. Endocrinology, 2000, $141: 2861-2869$.

7. EDDY E.M., WASHBURN T.F., BUNCH D.O. et al. : Targeted disruption of the estrogen receptor gene in male mice causes alteration of spermatogenesis and infertility. Endocrinology, 1996, 137 : 4796-4805.

8. ENMARK E., PELTO-HUIKKO M., GRANDIEN K. et al. : Human estrogen receptor B-gene structure, chromosomal localization, and expression pattern. J. Clin. Endocrinol. Metab., 1997, 82 : 4258-4265.

9. FISHER C.R., GRAVES K.H., PARLOW A.F., SIMPSON E.R. : Characterization of mice deficient in aromatase (ArKO) because of targeted disruption of the cypl9 gene. Proc. Nat. Acad. Sci., 1998, 95 : 6965-6970.

10. FISHER J., MILLAR M.R., MAJDIC G. et al. : Immunolocalisation of oestrogen receptor-alpha (ERalpha) within the testis and excurrent ducts of the rat and marmoset monkey from perinatal life to adulthood. J. Endocrinol., 1997, $153: 485-495$.

11 FUJIMURA T., TAKAHASHI S., URANO T. et al. : Differential expression of estrogen receptor beta (Erbeta) and its C-terminal truncated splice variant Erbetacx as prognostic predictors in human prostatic cancer. Biochem. Biophys. Res. Commun., 2001, $289: 692-696$.

12. GASKELL T.L., ROBINSON L.L.L., GROOME N.P., ANDERSON R.A., SAUNDERS P.T.K. : Differential expression of two estrogen receptor isoforms in the human fetal testis during the second trimester of pregnancy. J. Clin. Endocrinol. Metab., 2003 , in press.

13. GOYAL H.O., BARTOL F.F., WILEY A.A., NEFF C.W. : Immunolocalization of receptors for androgen and estrogen in male caprine reproductive tissues: unique distribution of estrogen receptors in efferent ductule epithelium. Biol. Reprod., 1997, $56: 90-101$. 
14. GREEN S., WALTER P., KUMAR V. et al. : Human oestrogen receptor cDNA : sequence, expression and homology to v-erb-A. Nature, 1986, 320:134-139.

15. HESS R.A., BUNICK D., BAHR J.M. : Sperm, a source of estrogen. Envir. Health Perspec., 1995, 103 : 59-62.

16. HESS R.A., BUNICK D., LEE K.H. et al. : A role for oestrogens in the male reproductive system. Nature, 1997, $390: 509-512$.

17. HESS R.A., GIST D.H., BUNICK D. et al. : Estrogen receptor $(\alpha \& B)$ expression in the excurrent ducts of the adult male rat reproductive tract. J. Androl., 1997, $18: 602-611$.

18. HESS R.A. : Oestrogen in fluid transport in efferent ducts of the male reproductive tract. Rev. Reprod., 2000, $5: 84-92$.

19. INOUE S., OGAWA S., HORIE K. et al. : An estrogen receptor beta isoform that lacks exon 5 has dominant negative activity on both ER $\alpha$ and ERB. Bioch. Biophy. Res. Commun., 2000, 279 : 814-819.

20. KLINGE C.M. : Estrogen receptor interaction with estrogen response elements. Nucl. Ac. Res., 2001, 29 : 2905-2919.

21. LUBAHN D.B., MOYER J.S., GOLDING T.S. et al. : Alteration of reproductive function but not prenatal sexual development after insertional disruption of the mouse estrogen receptor gene. Proc. Nat. Acad. Sci., 1993, $90: 11162-11166$.

22. LUBAHN D.B., TAYLOR J.A., SEO K., BUNICK D., HESS R.A. : Oestradiol receptor minus mice have abnormal seminiferous tubules, rete testis and efferent ductules. Program and Abstracts of 10th International Congress of Endocrinology, San Francisco, 1996 : Abstract P1-185.

23. MADDOCKS S., HARGREAVE T.B., REDDIE K. et al. : Intratesticular hormone levels and the route of secretion of hormones from the testis of the rat, guinea pig, monkey and human. Int. J. Androl., 1993, $16: 272-278$.

24. MAKINEN S., MAKELA S., WEIHUA Z. et al. : Localization of oestrogen receptors alpha and beta in human testis. Mol. Hum. Reprod., 2001, $7: 497-503$.

25. MOORE J.T., MCKEE D.D., SLENTZ-KESLER K. et al. : Cloning and characterisation of human estrogen receptor beta isoforms. Bioch. Biophy. Res. Com., 1998, 247 : 75-78.

26. MOSSELMAN S., POLMAN J., DIJKEMA R. : ERbeta : identification and characterization of a novel human estrogen receptor. F.E.B.S. Letters, 1996, $392: 49-53$.

27. NIE R., ZHOU Q., JASSIM E., SAUNDERS P.T.K., HESS R.A.: Differential expression of estrogen receptors $\alpha$ and $\beta$ in reproductive tracts of the adult male dog and cat. Biol. Reprod., 2002, $66: 1161-1168$.

28. NILSSON S., MAKELA S., TREUTER E. et al. : Mechanisms of estrogen action. Physiol. Rev., 2001, 81 : 1535-1565.

29. O'DONNELL L., MCLACHLAN R., WREFORD N., DE KRETSER D., ROBERTSON D. : Testosterone withdrawal promotes stage-specific detachment of round spermatids from rat seminiferous epithelium. Biol. Reprod., 1996, 55 : 895-901.

30. O'DONNELL L., ROBERTSON K.M., JONES M.E., SIMPSON E.R. : Estrogen and spermatogenesis. Endocr. Rev., 2001, $22: 289-318$.

31. OGAWA S., INOUE S., WATANABE T. et al. : The complete primary structure of human estrogen receptor beta (hER beta) and its heterodimerization with $\mathrm{ER}$ alpha in vivo and in vitro. Bioch. Biophys. Res. Com., 1998, 243 : 122-126.

32. OGAWA S., INOUE S., WATANABE T. et al. : Molecular cloning and characterization of human estrogen receptor $B c x$ : a potential inhibitor of estrogen action in human. Nucl. Ac. Res., $1998,26: 3505-3512$.

33. OLIVEIRA C.A., ZHOU Q., CARNES K. et al. : ER function in the adult male rat : short- and long-term effects of the antiestrogen ICI 182,780 on the testis and efferent ductules, without changes in testosterone. Endocrinology, 2002, $143: 2399-2409$.

34. PAYNE A., KELCH R., MUSICH S., HALPERN M. : Intratesticular site of aromatization in the human. J. Clin. Endocrinol. Metab., 1976, 42 : 1081-1087.

35. PAYNE A., YOUNGBLOOD G. : Regulation of expression of steroidogenic enzymes in Leydig cells. Biol. Reprod., 1995, 52 : 217-225.

36. ROBERTSON K., O'DONNELL L., JONES M. et al. : Impairment of spermatogenesis in mice lacking a functional aromatase (CYP19) gene. Proc. Nat. Acad. Sci., 1999, 96 : 7986-7991.

37. ROBERTSON K.M., SIMPSON E.R., LACHAM-KAPLAN O., JONES M.E.E. : Characterization of the fertility of male aromatase knockout mice. J. Androl., 2001, $22: 825-830$.

38. SAJI S., OMOTO Y., SHIMIZU C. et al. : Expression of estrogen receptor $(\mathrm{ER})$ Bcx protein in $\mathrm{ER} \alpha$-postive breast cancer: specific correlation with progesterone receptor. Cancer Res., 2002, $62: 4849-4853$.

39. SAUNDERS P.T., FISHER J.S., SHARPE R.M., MILLAR M.R.: Expression of oestrogen receptor beta (ER beta) occurs in multiple cell types, including some germ cells, in the rat testis. J. Endocrinol., 1998, 156 : R13-7.

40. SAUNDERS P.T.K., MILLAR M.R., WILLIAMS K. et al. : Differential expression of estrogen receptor-alpha and -beta and androgen receptor in the ovaries of marmoset and human. Biol. Reprod., 2000, 63 : 1098-1105.

41. SAUNDERS P.T.K., SHARPE R.M., WILLIAMS K. et al. : Differential expression of oestrogen receptor alpha and beta proteins in the testes and male reproductive system of human and nonhuman primates. Mol. Hum. Reprod., 2001, 7 : 227-236.

42. SAUNDERS P.T.K., MILLAR M.R., MACPHERSON S. et al. : Estrogen receptor beta (ERB1), and the estrogen receptor beta 2 splice variant (ERBcx/2), are expressed in distinct cell populations in the adult human testis. J. Clin. Endocrinol. Metab., 2002, $87: 2706-2715$.

43. SCOBIE G.S., MACPHERSON S., MILLAR M.R. et al. : Human estrogen receptors : differential expression of ERalpha and beta and the identification of ERbeta variants. Steroids, $2002,67: 985-992$.

44. SHETTY G., KRISHAMURTHY H., KRISHNAMURTHY H.N., BHATNAGAR A.S., MOUDGAL N.R. : Effect of longterm treatment with aromatase inhibitor on testicular function of adult bonnet monkeys ( $M$. radiata). Steroids, 1998, $63: 414$ 420.

45. TONG M.H., SONG W.C. : Estrogen sulfotransferase : discrete and androgen-dependent expression in the male reproductive 
tract and demonstration of an in vivo function in the mouse epididymis. Endocrinology, 2002, 143 : 3144-3151.

46. TURNER K.J., MACPHERSON S., MILLAR M.R. et al. : Development and validation of a new monoclonal antibody to mammalian aromatase. J. Endocrinol., 2002, $172:$ 21-30.

47. VAN PELT A.M., DE ROOIJ D.G., VAN DER BURG B. et al. : Ontogeny of estrogen receptor-beta expression in rat testis. Endocrinology, 1999, 140:478-483.

48. WILLIAMS K., MCKINNELL C., SAUNDERS P.T.K. et al. : Neonatal exposure to potent and environmental oestrogens and abnormalities of the male reproductive system in the rat : evidence for the importance of the androgen-oestrogen balance and assessment of relevance to man. Hum. Reprod. Update, 2001, 7 : 236-247.

49. ZHOU Q., CLARKE L., NIE R. et al. : Estrogen action and male fertility : roles of the sodium/hydrogen exchanger-3 and fluid reabsorption in reproductive tract function. Proc. Nat. Acad. Sci., 2001, $98: 14132-14137$.

50. ZHOU Q., NIE R., PRINS G.S. et al. : Localization of androgen and estrogen receptors in adult male mouse reproductive tract. $\mathrm{J}$. Androl., 2002, $23: 870-881$.

\section{ABSTRACT}

Oestrogen receptors in the human and primate testis and reproductive tract

Philippa T.K. SAUNDERS, Jayne E. SIERENS, Niegel P. GROOME*, Michael R. MILLAR

The impact of oestrogens on the male reproductive system remains the subject of intensive research activity and debate. Oestrogen action is mediated via high affinity intracellular receptors expressed in target tissues. Two subtypes of oestrogen receptor known as RE $\alpha$ (NR3A1) and ERB (NR3A2) have been cloned and $h E R B$ variant isoforms identified. In target cells these receptors can exist as homo- or heterodimers. We have used immunohistochemistry to examine the patterns of expression of ERs in human and non-human primates as a first step in determining the cellular targets for oestrogen action in the male.

RE $\alpha$ was detected in the epithelial cells of efferent ductules (ED) occasionally in epithelial and stromal cells within the epididymis but was undetectable in human or primate testes. Using a polyclonal antibody raised against the hinge domain of ERß, immunopositive staining was detected in multiple cell types within the testis and in epithelial and stromal cell nuclei throughout the male reproductive system (ED, epididymis, vas deferens, seminal vesicles, prostate) and in the bladder. We have also used monoclonal antibodies that distinguish between wild type, full-length ERB (ERB1), and a splice variant isoform called ERßCX/ERß2 that does not bind oestrogens. ERB1 and ERB2 proteins were both detected in human testis and have distinct but overlapping patterns of expression. ERß1 was also detected in ED, epididymis and vas.

In conclusion, oestrogen receptors are widely expressed in the male urogenital system and with the exception of the ED there are more cells that express ERß than RE $\alpha$. In the adult human the testicular cells most likely to be targets for oestrogens are round spermatids in which levels of expression of full-length wild type receptor (ERß1) are high.

Key words : spermatogenesis, oestrogen receptor, $E R ß$, spermatid 